\title{
Memantine Augmentation of Sertraline in Severity of Symptoms and Cognitive Function Among Patients with Obsessive-Compulsive Disorder: A Double-Blind Placebo-Controlled, Randomized Clinical Trial
}

\section{Sanaz Askari}

Iran University of Medical Sciences

\section{Saba Mokhtari}

University of Social Welfare and Rehabilitation

\section{Seyed Vahid Shariat}

Iran University of Medical Sciences

\section{Behnam Shariati}

Iran University of Medical Sciences

Masoomeh Yarahmadi

Iran University of Medical Sciences

Mohammadreza Shalbafan ( $\nabla$ shalbafan.mr@iums.ac.ir)

Iran University of Medical Sciences

\section{Research Article}

Keywords: Glutamate, memantine, Obsessive-Compulsive Disorder, Randomized controlled trial

Posted Date: August 17th, 2021

DOI: https://doi.org/10.21203/rs.3.rs-647493/v1

License: (c) (i) This work is licensed under a Creative Commons Attribution 4.0 International License. Read Full License 


\section{Abstract}

Background: Medications currently recommended for the treatment of Obsessive-Compulsive Disorder (OCD) usually decrease the severity of the symptoms by $20-30 \%$, and $40-60 \%$ of OCD patients do not achieve satisfactory treatment. In this study, the main objective was to investigate the effectiveness of memantine, which is a non-competitive N-Methyl-D-aspartate (NMDA) receptor antagonist, as an adjunct therapy to sertraline, a selective serotonin reuptake inhibitor (SSRI), to improve severity of symptoms and cognitive function among patients with obsessive-compulsive disorder.

Methods: 70 patients who based on Diagnostic and Statistical Manual of Mental Disorders (DSM-5) criteria were diagnosed with OCD, and had a Yale-Brown obsessive compulsive scale (Y-BOCS) score of more than 21, were recruited in a placebo controlled, double-blinded, parallel-group, clinical trial of 12 weeks to receive either memantine (10 mg twice daily) and sertraline (100 mg daily initially followed by $200 \mathrm{mg}$ daily after week 4) or placebo and sertraline. The primary outcome was OCD symptoms measured by the Y-BOCS, moreover, the executive function and the cognition of participants was measured by the Wisconsin Card Sorting Test (WCST).

Results: Y-BOCS score in total, obsession and compulsion subscales significantly dropped in both groups; however, there was not a significant difference between them. In comparison of cognition, memantine group showed a greater response in number of categories subscale in the WCST ( $p$ value<0.001). No major adverse effects were observed in any of the groups.

Conclusion: Our findings suggest a probable effect of memantine as adjuvant therapy to sertraline on cognitive function of patients with OCD as well as its safety and tolerability in comparison with placebo. Nevertheless, the current results don't support the efficacy of memantine as an adjunctive agent to sertraline for improving severity of symptoms among patients with OCD.

Trial registration: The trial was registered at the Iranian Registry of Clinical Trials on 2019-10-04 (www.irct.ir; IRCT ID: IRCT20170123032145N4).

\section{Background}

Obsessive-Compulsive Disorder (OCD) affects $1-3 \%$ of worldwide population $(1,2)$. OCD is characterized by recurrent, unwanted and intrusive thoughts, urges or images which causes anxiety and discomfort, and/or by repetitive behaviors or mental acts that tries to prevent or reduce the associated anxiety $(3,4)$. If left untreated, the course is chronic (5). OCD impairs quality of life severely and causes impairment in all aspects of function $(6,7)$. It has shown that patients with OCD have significant differences, with the control group, in tests related to verbal memory, psychomotor speed and global attention, visuospatial and executive functions, indicating poorer performance $(8,9)$. Cognitive impairments, particularly deficiencies in executive functions and information processing, considerably suppress patient's abilities to gain, maintain and relearn the skills needed for suitable performances and association between poorer 
neuropsychological performance and real-life functioning has been shown in OCD patients $(10,11)$. Apart from the public health impact, OCD also results in a considerable economic burden(12).

Currently, selective serotonin reuptake inhibitors (SSRIs) and/or cognitive behavioral therapy (CBT), are considered to be first-line treatments for $\operatorname{OCD}(13,14)$. Notwithstanding the effectiveness of CBT as a non-pharmacological treatment, it has several disadvantages such as delayed clinical response, limited access, and high cost(15). SSRIs usually reduce the Obsessive-Compulsive Disorder symptoms by as much as $20-30 \%$ and in only $40-60 \%$ of patients with OCD Satisfactory treatment is obtained $(16,17)$.

The cortico-striato-thalamo-cortical (CSTC) circuits, driven by the excitatory neurotransmitter glutamate, are described to be involved in $\mathrm{OCD}(18)$. Glutamate has an important role in many physiological processes including memory, cognition and learning(19). The striatum is an important brain region in the pathophysiology of OCD and is responsible for motor and cognitive actions(20). Glutamatergic neurons are the most abundant neurons in cell migration within the striatum and migration is also tightly controlled by glutamate(21). Some studies have shown that glutamatergic over-activity, increased glutamate levels in cerebrospinal fluid (CSF), and polymorphism of N-methyl-D-aspartate (NMDA) receptor's gene coding, play a part in OCD occurrence(22-25). Due to high proportion of resistance to SSRI treatment, the focus has shifted to the effect of glutamate and the CSTC brain circuit(26). Also there is evidence suggesting that the temporal lobe $(T L)$ has an important role in the brain pathogenesis of OCD (27-29).

Memantine is a non-competitive NMDA receptor antagonist approved for Alzheimer's disease in many countries, with a good safety profile, being studied in a variety of psychiatric disorders(30). It may decrease hyperactivity of the direct pathway of CSTC(26). Memantine has a targeted de-excitation effect in the temporal lobes on the glutamatergic system and connected brain regions, that might further reduce OCD symptoms(28). The specific effect of memantine on temporal lobe can be even more helpful in certain patients and subtypes with specific deficits in cognition and maladaptive compensatory memory processes(26).

Open-label studies(31), single (32) and double-blind randomized controlled trials (RCTs) $(33,34)$ show benefits of adding memantine to ongoing SSRI in treatment of OCD. As methodological issues exist with each of these trials and inconsistent findings, and lack of studies on effect of memantine on cognitive impairments in OCD patients(20), this study aimed to investigate the benefits of memantine augmentation therapy with sertraline in reduction of OCD symptoms and cognitive impairments in OCD patients compared to sertraline plus placebo.

\section{Methods}

\section{Trial setting and design}

A 12-week, randomized, double-blind, placebo-controlled, parallel-group trial was performed at the outpatient clinics of Iran Psychiatric Hospital and Tehran Institute of Psychiatry (affiliated with Iran 
University of Medical Sciences, Tehran, Iran).

Participants were randomized to groups with a random permuted block method (ratio of 1:1 and blocks of four). The allocated group of each participant was printed sequentially and enveloped in a nontransparent and sealed envelope similar in appearance, using the random permuted block. The allocation was not in reach of the participants and outcome assessors. The outcome assessor, randomizer, and statistical analyzer each were separate individuals and all of them were blinded to allocation. Additionally, memantine and placebo tablets were similar in size, shape, color, and odor.

\section{Participants}

Patients, aged 18-60 years, with a clinical diagnosis of OCD based on the Diagnostic and Statistical Manual of Mental Disorders, 5th Edition (DSM-5) criteria, were screened for the study (35). Those with a Yale-Brown Obsessive Compulsive Scale (Y-BOCS) score of $\geq 21$ (moderate to-severe OCD) were included (36).

The patients attending to the clinics were consecutively checked for the inclusion criteria and recruited until the sample size was achieved. All of the patients enrolled in the study were assessed with a structured clinical interview designed in accordance with the DSM-5 by an expert psychiatrist (35).

The exclusion criteria were :1) comorbid axis I disorders; 2) a life threatening psychiatric symptoms (such as suicidal ideation); 3) serious medical or neurological conditions; 4) mental retardation (based on clinical judgment); 5) substance dependence (other than nicotine) 6) pregnancy/breast feeding; 7) history of severe allergy to or contraindication for the use of memantine or sertraline; 8 ) history of complete response with sertraline 9 ) history of previous psychosurgery for OCD; 10) history of treatment-refractory OCD. During the conduction of the trial, patients were not permitted to participate in any psychotherapeutic treatment. Furthermore, patients were excluded if they used any psychotropic drugs in the last 6 weeks.

\section{Interventions}

Eligible participants were randomized to receive either memantine, $10 \mathrm{mg}$ twice per day, or placebo for 12 weeks. All participants, regardless of group assignment, $100 \mathrm{mg} /$ day for 4 weeks and then gradually increased to $200 \mathrm{mg} /$ day. To minimize the side effects, the dosage of sertraline was slowly increased every week.

\section{Outcome}

Y-BOCS was used for assessment of patients at baseline and at weeks $0,4,8$, and 12 of therapy. Y-BOCS provides a rating scale for severity of obsessive-compulsive symptoms (34-36). This clinician-rated scale contains 10 questions, each item rated from 0 (no symptoms) to 4 (extreme symptoms)(37). The psychometric properties of the Persian version of Y-BOCS are approved in previous studies $(14,16,36)$. 
The total score of the Y-BOCS difference between the baseline and the week 12 among the two groups was the primary outcome measure of the trial.

We used Wisconsin Card Sorting Test (WSCT) to examine participant's executive function at weeks 0 and 12 of therapy. The WCST was developed by Berg and Grant to assess flexibility in thinking and shifting to a new response to changing environmental contingencies(38). It is used as a measure of executive function $(39,40)$. The WCST consists of four stimulus cards and the subject receives two sets of 64 response cards. The subject should match response cards to the stimulus cards and receive feedback whether he or she is right or wrong on each trial. Important scales in the WCST include the number of categories achieved, the number of perseverative errors, and the number of set-loss errors(41).

The difference of each scale of the WCST between baseline and the end of the trial between the two groups were measured to assess the executive function and cognition of participants.

Moreover, adverse effects were monitored each four weeks using a systematic questionnaire and three open questions to include any other side effects not included in the questionnaire. In case of observation of any serious adverse effects during the course of therapy, a physician assessed the potential role of the medication in inducing the adverse effects and omitted the patient from the trial.

Missing data was imputed with last observation carried forward (LOCF) method.

\section{Sample size and statistical analysis}

With a between-group difference of five points in Y-BOCS score, type I error of $5 \%$ and power of $90 \%$, using G-power 3.1.9.2 we calculated a sample size of 58 (29 in each group). Considering a drop-out rate of $20 \%$, our final sample size was calculated 70 (35 in each group).

IBM SPSS Statistic 16.5 (IBM Corporations, Somers, New York, USA) was used for the statistical analysis. Continuous variables were reported as mean $\pm S D$ and categorical variables as $\mathrm{n}(\%)$. Mean differences (MDs) between groups were reported as MDs (95\% confidence interval (CI)). Fisher's exact test, or $\chi 2$-test was used for the comparison among categorical variables. The independent samples t-test was conducted for the comparison of continuous variable values, respectively. The comparison of Y-BOCS total and subscale score changes and WCST scale scores in and between groups during the 12-week course of study was achieved by performing General linear model repeated measures. Whenever sphericity of the data could not be assumed using the Mauchly's test of sphericity, the homogeneity of the variance is tested with Levene's test. Score changes from baseline in the participants of each group was examined using the paired sample t-test. A p-value level of $\leqslant 5 \%$ was defined as significant.

\section{Results}

\section{Participants}


One hundred and four patients were screened primarily, while 70 patients were recruited (randomly assigned to groups of memantine+sertraline or placebo+sertraline), and 53 patients completed the trial. Trial flow diagram and number of dropouts are represented in Figure 1. None of the dropouts was in regard of adverse effects or substance use. In first 4weeks there were 35 patients in memantine group and 30 patients in placebo group that the Baseline characteristics of each group are summarized separately in Table 1.

Table 1

Baseline characteristics of participants in first 4weeks 


\begin{tabular}{|c|c|c|c|c|c|c|}
\hline & & Treatment G & & & & \\
\hline & & $\begin{array}{l}\text { memantine+ } \\
(n=35)\end{array}$ & rtraline & $\begin{array}{l}\text { placebo+s } \\
(n=30)\end{array}$ & & $\begin{array}{l}\mathrm{P} \\
\text { value }\end{array}$ \\
\hline & & Mean $\pm S D$ & $\begin{array}{l}\text { Count } \\
(\%)\end{array}$ & Mean $\pm S D$ & $\begin{array}{l}\text { Count } \\
(\%)\end{array}$ & \\
\hline Age (years) & & $35.03 \pm 11.35$ & & $334.83 \pm 10$ & & \\
\hline Gender & Female & & 27 & & 17 & 0.07 \\
\hline & & & $(77.1 \%)$ & & $(56.7 \%)$ & \\
\hline & Male & & 8 & & 13 & \\
\hline & & & $(22.9 \%)$ & & $(43.3 \%)$ & \\
\hline Education & Illiterate & & 0 & & 1 & 0.30 \\
\hline & & & $(0.0 \%)$ & & $(3.3 \%)$ & \\
\hline & Primary & & 1 & & 2 & \\
\hline & & & $(2.9 \%)$ & & $(6.7 \%)$ & \\
\hline & Secondary & & 9 & & 5 & \\
\hline & & & $(25.7 \%)$ & & $(16.7 \%)$ & \\
\hline & High school & & 9 & & 13 & \\
\hline & & & $(25.7 \%)$ & & $(43.3 \%)$ & \\
\hline & $\begin{array}{l}\text { University } \\
\text { Education }\end{array}$ & & $\begin{array}{l}16 \\
(45.7 \%)\end{array}$ & & $\begin{array}{l}9 \\
(30.0 \%)\end{array}$ & \\
\hline Marital status & Single & & $\begin{array}{l}18 \\
(51.4 \%)\end{array}$ & & $\begin{array}{l}11 \\
(36.7 \%)\end{array}$ & 0.08 \\
\hline & Married & & $\begin{array}{l}14 \\
(40.0 \%)\end{array}$ & & $\begin{array}{l}17 \\
(56.7 \%)\end{array}$ & \\
\hline & Divorced & & 0 & & 2 & \\
\hline & & & $(0.0 \%)$ & & $(6.7 \%)$ & \\
\hline & Separated & & 3 & & 0 & \\
\hline & & & $(8.6 \%)$ & & $(0.0 \%)$ & \\
\hline Employment & Employed & & 18 & & 18 & 0.71 \\
\hline & & & $(51.4 \%)$ & & & \\
\hline & Unemployed & & $\begin{array}{l}7 \\
(20.0 \%)\end{array}$ & & 4 & \\
\hline
\end{tabular}




\begin{tabular}{|c|c|c|c|c|c|c|}
\hline & Housewife & & 10 & & 8 & \\
\hline & & & $(28.6 \%)$ & & $(26.7 \%)$ & \\
\hline \multirow{4}{*}{$\begin{array}{l}\text { Previous } \\
\text { treatment }\end{array}$} & \multirow[t]{2}{*}{ Yes } & & 4 & & 2 & \multirow[t]{4}{*}{0.50} \\
\hline & & & $(11.4 \%)$ & & $(6.7 \%)$ & \\
\hline & \multirow[t]{2}{*}{ No } & & 31 & & \multirow{2}{*}{$\begin{array}{l}28 \\
(93.3 \%)\end{array}$} & \\
\hline & & & $(88.6 \%)$ & & & \\
\hline \multirow{3}{*}{$\begin{array}{l}\text { Y-BOCS score } \\
\text { (week 0) }\end{array}$} & Total & $27.88 \pm 5.65$ & & $30.11 \pm 5.79$ & & 0.12 \\
\hline & Obsession & $15.07 \pm 2.57$ & & $15.53 \pm 2.50$ & & 0.46 \\
\hline & Compulsion & $12.70 \pm 4.30$ & & $14.57 \pm 3.81$ & & 0.07 \\
\hline \multirow{3}{*}{$\begin{array}{l}\text { WCST score } \\
\text { (week 0) }\end{array}$} & Error & $22.89 \pm 9.85$ & & $22.09 \pm 10.63$ & & 0.80 \\
\hline & Categories & $3.36 \pm 1.77$ & & $3.90 \pm 1.86$ & & 0.35 \\
\hline & Perseveration & $6.15 \pm 5.54$ & & $7.88 \pm 9.02$ & & 0.47 \\
\hline
\end{tabular}

\section{Y-BOCS total score}

The baseline Y-BOCS total score's difference was not significant between the groups $(\mathrm{MD}(95 \% \mathrm{Cl})=$ $-2.23(-5.07-0.61)$, p-value $=0.12$, Table 1$)$. Total $Y$-BOCS score changes from baseline in memantine group at fourth and $12^{\text {th }}$ week of the study was MD $(95 \% \mathrm{Cl})=4.85(1.77-7.92)$ (p-value $\left.<0.001\right)$ at week 4 and $M D(95 \% \mathrm{Cl})=16.66(13.62-19.69)(p$-value $<0.001)$ at $12^{\text {th }}$ week, respectively. Similarly, participants in the placebo group experienced significant Y-BOCS total score drop at fourth and $12^{\text {th }}$ week into the trial $\left(\mathrm{MD}(95 \% \mathrm{Cl})=7.88(4.48-11.27)(\mathrm{p}\right.$-value $<0.001)$ in the $4^{\text {th }}$ week and $\mathrm{MD}(95 \% \mathrm{Cl})=20.61$ (17.35-23.86) ( $p$-value<0.001) in the end) General linear model repeated measures revealed no significant difference for the time between memantine and placebo groups ( $p$-value=0.71) (Figure 2).

\section{Y-BOCS obsession subscale score}

The baseline Y-BOCS obsession subscale score was not significantly different among treatment groups $(\mathrm{MD}(95 \% \mathrm{Cl})=-0.46$ (-1.72-0.80), p-value=0.46 (Table1)). Obsession Y-BOCS score changes from baseline in memantine group at fourth and $12^{\text {th }}$ week of the study were MD $(95 \% \mathrm{Cl})=2.62(1.20-4.03)(\mathrm{p}$ value $<0.001)$ at week 4 and $\mathrm{MD}(95 \% \mathrm{Cl})=8.88(7.38-10.37)(\mathrm{p}$-value $<0.001)$ at $12^{\text {th }}$ week, respectively. Similarly, participants in the placebo group experienced significant Y-BOCS total score drop at 12 weeks into the trial, while their score change mean differences were MD $(95 \% \mathrm{Cl})=10.23(8.82-11.63)(\mathrm{p}$-value 
$<0.001)$ and in the $4^{\text {th }}$ week $(\mathrm{MD}(95 \% \mathrm{Cl})=3.80(2.13-5.46)(\mathrm{p}$-value $<0.001))$ respectively. The timextreatment group interaction analysis by general linear model repeated-measures revealed no significant difference between groups ( $p$-value= 0.33) (Figure 3).

\section{Y-BOCS compulsion subscale score}

The baseline Y-BOCS compulsion subscale score was not significantly different among treatment groups $(\mathrm{MD}(95 \% \mathrm{Cl})=-1.87$ (-3.89_0.15), p-value=0.07 (Table1)). Compulsion Y-BOCS score changes from baseline in both groups at $4^{\text {th }}$ and $12^{\text {th }}$ week of the study. Memantine group difference in $4^{\text {th }}$ was MD $(95 \% \mathrm{Cl})=2.33(0.15-4.50)(\mathrm{p}$-value 0.03$)$ and $\mathrm{MD}(95 \% \mathrm{Cl})=7.80(5.77-9.82)(\mathrm{p}$ value $<0.001)$ in the $12^{\text {th }}$ week and placebo group experienced significant Y-BOCS compulsion score drop at week (4 MD (95\% $\mathrm{Cl})=4.15(2.07-6.28)(\mathrm{p}$-value $<0.001))$ and in week $12(\mathrm{MD}(95 \% \mathrm{Cl})=10.42(8.34-12.49)(\mathrm{p}-$ value $<0.001)$ ), respectively but the timextreatment group interaction analysis by general linear model repeated-measures revealed no significant difference ( $p$-value=0.87) (Figure 4).

\section{Table 2}

Comparison of Yale-Brown obsessive-compulsive scale (Y-BOCS) subscales score change from baseline for treatment groups 


\begin{tabular}{|c|c|c|c|c|c|c|c|}
\hline \multicolumn{2}{|c|}{$\begin{array}{l}\text { Y-BOCS subscale score } \\
\text { reduction }\end{array}$} & \multicolumn{6}{|c|}{ Treatment group } \\
\hline & & \multicolumn{3}{|c|}{ memantine+sertraline } & \multicolumn{3}{|c|}{ placebo+sertraline } \\
\hline & & Mean $\pm S D$ & $\begin{array}{l}\mathrm{MD}(95 \% \\
\mathrm{Cl})\end{array}$ & $\begin{array}{l}\mathrm{p}- \\
\text { Value }\end{array}$ & Mean $\pm S D$ & $\begin{array}{l}\mathrm{MD}(95 \% \\
\mathrm{Cl})\end{array}$ & $\begin{array}{l}\mathrm{p}- \\
\text { Value }\end{array}$ \\
\hline \multirow[t]{4}{*}{ Total } & \multirow[t]{2}{*}{ Week 4} & \multirow[t]{2}{*}{$23.03 \pm 6.42$} & 4.85 & \multirow[t]{2}{*}{$<0.001$} & \multirow[t]{2}{*}{$22.23 \pm 6.88$} & 7.88 & \multirow[t]{2}{*}{$<0.001$} \\
\hline & & & $(1.77-7.92)$ & & & $\begin{array}{l}(4.48- \\
11.27)\end{array}$ & \\
\hline & \multirow{2}{*}{$\begin{array}{l}\text { Week } \\
12\end{array}$} & \multirow[t]{2}{*}{$11.22 \pm 6.26$} & 16.66 & \multirow[t]{2}{*}{$<0.001$} & \multirow[t]{2}{*}{$9.5 \pm 6.34$} & 20.61 & \multirow[t]{2}{*}{$<0.001$} \\
\hline & & & $\begin{array}{l}(13.62- \\
19.69)\end{array}$ & & & $\begin{array}{l}(17.35- \\
23.86)\end{array}$ & \\
\hline \multirow[t]{4}{*}{ Obsession } & \multirow[t]{2}{*}{ Week 4} & \multirow[t]{2}{*}{$12.55 \pm 3.01$} & 2.62 & \multirow[t]{2}{*}{$<0.001$} & \multirow[t]{2}{*}{$11.73 \pm 3.67$} & 3.80 & \multirow[t]{2}{*}{$<0.001$} \\
\hline & & & $(1.20-4.03)$ & & & $\begin{array}{l}(2.13- \\
5.46)\end{array}$ & \\
\hline & \multirow{2}{*}{$\begin{array}{l}\text { Week } \\
12\end{array}$} & \multirow[t]{2}{*}{$6.29 \pm 3.33$} & 8.88 & \multirow[t]{2}{*}{$<0.001$} & \multirow[t]{2}{*}{$5.3 \pm 2.76$} & 10.23 & \multirow[t]{2}{*}{$<0.001$} \\
\hline & & & $\begin{array}{l}(7.38- \\
10.37)\end{array}$ & & & $\begin{array}{l}(8.82- \\
11.63)\end{array}$ & \\
\hline \multirow[t]{2}{*}{ Compulsion } & Week 4 & $10.37 \pm 4.16$ & $\begin{array}{l}2.33(0.15- \\
4.50)\end{array}$ & 0.03 & $10.42 \pm 4.15$ & $\begin{array}{l}4.15 \\
(2.01- \\
6.28)\end{array}$ & $<0.001$ \\
\hline & $\begin{array}{l}\text { Week } \\
12\end{array}$ & $4.90 \pm 3.42$ & $\begin{array}{l}7.80 \\
(5.77- \\
9.82)\end{array}$ & $<0.001$ & $4.15 \pm 3.92$ & $\begin{array}{l}10.42 \\
(8.34- \\
12.49)\end{array}$ & $<0.001$ \\
\hline
\end{tabular}

\section{WCST number of errors subscale score}

The baseline WCST number of errors subscale score did not significantly differ among treatment groups $(\mathrm{MD}(95 \% \mathrm{Cl})=0.80(-5.78-7.38), \mathrm{p}$-value $=0.80$ (Table1)). WCST number of errors score reduced in memantine group (MD $(95 \% \mathrm{Cl})=5.21(-1.11-11.53))$ between week 0 to 12 but the difference was not significant. ( $\mathrm{p}$-value $=0.10$ ). It did not change significantly in placebo group in the course of the trial. (MD $(95 \% \mathrm{Cl})=-0.29(-5.73-6.32), \mathrm{p}$-value $=0.92)$ and general linear model repeated measures revealed no significant difference between two groups ( $p$ value= 0.53 ) (Figure 5$)$.

\section{WCST number of categories subscale score}

The baseline WCST number of categories subscale score did not significantly differ among treatment groups (MD (95\% Cl)=-0.54 (-1.70-0.62), p-value=0.35 (Table1)). WCST number of categories score changed significantly between week 0 to 12 , in memantine group ((MD $(95 \% \mathrm{Cl})=-1.48(-2.62--0.33), \mathrm{p}-$ 
value $=0.01)$ but it did not change significantly in placebo group.(MD $(95 \% \mathrm{Cl})=0.19(-0.93-1.31), \mathrm{p}-$ value $=0.73$ ) and general linear model repeated measures revealed significant difference between two groups (10.938 (1.38) $=0.77 p$-value<0.001) (Figure 6).

\section{WCST number of perseverative errors subscale score}

The baseline WCST number of perseveration subscale score did not significantly differ among treatment groups (MD (95\% Cl)=-1.73 (-6.58-3.12), p-value=0.47 (Table1)). WCST number of perseveration score did not change significantly between week 0 to 12 , in both groups. (MD $(95 \% \mathrm{Cl})=2.05(-1.43-5.53), \mathrm{p}$ value $=0.24$ in memantine group and $\mathrm{MD}(95 \% \mathrm{Cl})=2.12(-2.22-6.48), \mathrm{p}$-value $=0.33$ in placebo group) and general linear model repeated measures revealed no significant difference between two groups $(p$ value= 0.40) (Figure 7).

\section{Adverse effects}

Adverse events were recorded during the study. Side effects were mild and did not result in withdrawal. Frequency of side effects was not different between the two groups (Table 3).

\section{Table 3}

Frequency of adverse events in the two groups

\begin{tabular}{|c|c|c|c|c|c|}
\hline \multirow[t]{3}{*}{ Adverse events } & \multicolumn{5}{|c|}{ Trearment group } \\
\hline & \multicolumn{2}{|c|}{ memantine+sertraline } & \multicolumn{2}{|c|}{ placebo+sertraline } & \multirow[t]{2}{*}{ p-value } \\
\hline & $\mathrm{N}$ & $\%$ & $\mathrm{~N}$ & $\%$ & \\
\hline Muscle pain & 2 & 5.7 & 2 & 6.7 & 0.87 \\
\hline Headache & 2 & 5.7 & 2 & 6.7 & 0.87 \\
\hline Diarhea & 1 & 2.9 & 0 & 0 & 0.35 \\
\hline Constipation & 0 & 0 & 0 & 0 & 1 \\
\hline Decreased libido & 5 & 14.3 & 3 & 10 & 0.60 \\
\hline Decreased appetite & 5 & 14.3 & 3 & 10 & 0.60 \\
\hline Lightheadness & 1 & 2.9 & 0 & 0 & 0.35 \\
\hline Palpitation & 0 & 0 & 1 & 3.3 & 0.28 \\
\hline Insomnia & 3 & 8.6 & 0 & 0 & 0.10 \\
\hline Vomiting & 3 & 8.6 & 1 & 3.3 & 0.38 \\
\hline
\end{tabular}




\section{Discussion}

Results of the current clinical trial don't show a significant difference in the improvement of severity of symptoms of patients with moderate to severe OCD with augmentation of memantine $(10 \mathrm{mg} /$ twice per day) to sertraline through 12 weeks of the study. Although, the findings indicate a significant improvement of executive function of the patients of memantine arm in Categories, one of the items of WSCT, in comparison with the placebo group. Interestingly, observed adverse effects were not suffering nor life-threatening in both groups and none of the adverse effects was, significantly, higher in the memantine group than the placebo group.

To the best of our knowledge, four previous randomized-placebo controlled clinical trial have investigated the efficacy of memantine as an adjunctive agent to standard serotonergic medications for the treatment of OCD and reported complex findings of its efficacy, whereas this is the first 12-week double-blind, placebo-controlled clinical trial to evaluate the efficacy of memantine on the severity of symptoms as well as the cognitive function of patients with moderate to severe $O C D$, as an augmentation to sertraline.

Our results are in agreement with Farnia et al. report that investigated the efficacy of memantine plus fluoxetine in an 8-week, three arms trial with gabapentin plus fluoxetine and placebo plus fluoxetine in outpatients with OCD. Similar to our report, they didn`t show a significant difference between arms based on neither YBOCS total score nor response rate (33). We report the same finding in our 12-week trial about the augmentation of memantine to another approved SSRI, sertraline. Nevertheless, Ghaleiha et al. reported memantine (10 mg/ twice per day) plus fluvoxamine more efficient than placebo plus fluvoxamine in an 8-week double-blinded, randomized, controlled trial among thirty-eight patient in the treatment of severity of symptoms and response rate of patients with moderate to severe OCD patients. In agreement with our trial, they observed no significant adverse effect in the memantine group in comparison with the placebo group(42). Our trial provided longer follow-up as well as, to some extent, a larger sample size. The inconsistency of these two trials might be on account of augmenting memantine to different medications.

Modarresi et al. investigated the efficacy of memantine $(10 \mathrm{mg} /$ twice per day) as an augmented agent for the treatment of patients with Serotonin Reuptake Inhibitors (SRIs) treatment-refractory OCD among thirty-two participants in a 12-week trial. Moreover, they indicated a significant reduction of severity of symptoms based on YBCS as well as more response rate in the memantine group than the placebo group. In addition, similar to our findings, they reported memantine as a well-tolerated and safe agent(34). The results of their study are hardly comparable to ours due to substantial differences between recruited participants. Their trial was performed among SRIs treatment-refractory patients, while we recruited patients with moderate to severe symptoms with non-refractory OCD. Standard medications were mixed among both groups, whereas we used sertraline with the same dose among both groups to elaborate more comparable results between each group.

In the same vein, Haghighi and his colleagues performed a 12-week placebo-controlled trial on 29 inpatients with OCD to evaluate the efficacy of memantine (5-10 mg/ day) as an adjunctive agent to an 
SSRI or clomipramine. They reported YBOCS decreased, significantly, in the memantine group in comparison with the placebo group(35).

Two trials of Bakhla et al., and Aboujaoude et al., are not easily comparable with our study due to their different designs as open-label trials(31, 43). Moreover, study of Stewart et al., is a single-blinded casecontrol study that cannot be compared with our study as double-blinded controlled trial. Same as previously mentioned trial findings of the study is not easily comparable with our findings due to difference of patient setting, the dosage of memantine as well as standard medications.

Although some of the evidence presented supports the efficacy and safety of glutamatergic medications like memantine in the treatment of OCD patients, a recent review article suggested more well-conducted in vivo and basic experimental studies(20).

Additionally, we evaluated the effect of memantine as an augmentation to sertraline for improvement of cognitive impairment of patients with moderate to severe OCD that is one of the most disabling manifestations of this neuropsychiatric disorder $(8,9,12)$. To the best of our knowledge, our study is the first double-blind, placebo-controlled, clinical trial for this purpose. Despite the efficacy of the agent on cognitive impairment of other neuropsychiatric conditions, more specifically Alzheimer is well- known(44), our finding showed a probable efficacy of augmentation of memantine to sertraline in this manner, however, more well-designed with a larger sample size as well as long follow-up are necessary.

\section{Limitations}

Despite numerous strengths of the current study, there are some important limitations for our trial that should be considered by further studies. Although the sample size of our study was larger than previous studies, this is a clinical trial with small sample size. In addition, as we know, based on delayed response in OCD patients in comparison with some other neurotic psychiatric disorders like depression, a 12-week follow-up seems to be a short time to observe the efficacy of the treatment on the severity of symptoms and cognitive functioning of the patients. Moreover, we only used WCST to examine the executive function and cognition of our participants. Using multiple tests to examine different aspects of cognition and using functional brain imaging and electroencephalography can show the purpose of this study, even more clear. Therefore, designing multi-center trials with a large sample size, with multiple tools to examine cognition and executive function, and longer follow-up is suggested. The effect of improved cognition on quality of life of patients was not the purpose of our study and was not examined by us. Additional studies on this concept is suggested. Finally, we recruited patients with non-refractory OCD in the study, and generalization of the findings to this group of patients is not reasonable.

\section{Conclusion}

Our findings suggest a probable effect of memantine as adjuvant therapy to sertraline on cognitive function of patients with $O C D$ as well as its safety and tolerability in comparison with placebo. 
Nevertheless, the current results don't support the efficacy of memantine as an adjunctive agent to sertraline for improving the severity of symptoms among patients with OCD. Based on mixed results about the efficacy of memantine on OCD symptoms, further trials are necessary.

\section{Abbreviations}

Obsessive-Compulsive Disorder: OCD; N-Methyl-D-aspartate: NMDA; selective serotonin reuptake inhibitor: SSRI; Diagnostic and Statistical Manual of Mental Disorders: DSM-5; Yale-Brown obsessive compulsive scale: Y-BOCS; Wisconsin Card Sorting Test: WCST; Cognitive Behavioral Therapy: CBT; Cortico-striatothalamo-cortical (CSTC); Cerebrospinal fluid: CSF; Temporal lobe: TL; Randomized controlled trial: RCT; Mean difference: MD; confidence interval: $\mathrm{Cl}$; standard deviation: SD

\section{Declarations}

\section{Ethics approval and consent to participate}

The trial was approved by the ethics committee of Iran University of Medical Sciences institutional review board (IR.IUMS.REC.1398.640) and conducted according to the Declaration of Helsinki and subsequent revisions. Written informed consent was obtained from all participants. Patients were informed that their participation was a voluntary activity and that they had the right to leave the study at any time with no negative effect on their treatment. The trial was registered at the Iranian Registry of Clinical Trials (www.irct.ir; IRCT ID: IRCT20170123032145N4).

\section{Consent for publication}

Not applicable

\section{Availability of data and materials}

The datasets used and analyzed during the current study are available from the corresponding author on reasonable request.

\section{Competing interests}

The authors have no conflicts of interest to report.

\section{Funding}


The authors disclose receipt of the following financial support for the research, authorship, and/or publication of this article: This study was funded by Iran University of Medical Sciences (Grant no: 98-237-15669).

\section{Authors' contributions}

SA, SVS, BS and MS made substantial contributions to the conception and design of the work. SA, BS, MY and MS have substantial contribution in data gathering. SVS analyzed and interpreted the data. SA, $\mathrm{SM}$, and MS have major contribution in writing the manuscript. All authors read and approved the final manuscript.

\section{Acknowledgement}

This study was Dr. Sanaz Askari's postgraduate thesis toward the Iranian Board of Psychiatry.

\section{References}

1. Karno M, Golding JM, Sorenson SB, Burnam MA. The epidemiology of obsessive-compulsive disorder in five US communities. Archives of general psychiatry. 1988;45(12):1094-9.

2. Sasson Y, Zohar J, Chopra M, Lustig M, lancu I, Hendler T. Epidemiology of obsessive-compulsive disorder: a world view. Journal of Clinical Psychiatry. 1997;58(12):7-10.

3. American Psychiatric Association. Diagnostic and statistical manual of mental disorders (DSM-5®): American Psychiatric Pub; 2013.

4. Hirschtritt ME, Bloch MH, Mathews CA. Obsessive-compulsive disorder: advances in diagnosis and treatment. Jama. 2017;317(13):1358-67.

5. Thomsen PH. Obsessive-compulsive disorders. European child \& adolescent psychiatry. 2013;22(1):23-8.

6. Albert U, Maina G, Bogetto F, Chiarle A, Mataix-Cols D. Clinical predictors of health-related quality of life in obsessive-compulsive disorder. Comprehensive psychiatry. 2010;51(2):193-200.

7. DuPont RL, Rice D, Shiraki S, Rowland C. Economic costs of obsessive-compulsive disorder. Medical interface. 1995;8(4):102-9.

8. Lucey J, Burness C, Costa D, Gacinovic S, Pilowsky L, Ell P, et al. Wisconsin Card Sorting Task (WCST) errors and cerebral blood flow in obsessive-compulsive disorder (OCD). British Journal of Medical Psychology. 1997;70(4):403-11.

9. Tükel R, Gürvit H, Ertekin BA, Oflaz S, Ertekin E, Baran B, et al. Neuropsychological function in obsessive-compulsive disorder. Comprehensive psychiatry. 2012;53(2):167-75.

10. Keefe RS. The contribution of neuropsychology to psychiatry. The American journal of psychiatry. 1995. 
11. Perna G, Cavedini P, Harvey PD, Di Chiaro NV, Daccò S, Caldirola D. Does neuropsychological performance impact on real-life functional achievements in obsessive-compulsive disorder? A preliminary study. International journal of psychiatry in clinical practice. 2016;20(4):224-31.

12. Olesen J, Gustavsson A, Svensson M, Wittchen HU, Jönsson B, Group CS, et al. The economic cost of brain disorders in Europe. European journal of neurology. 2012;19(1):155-62.

13. Foa EB, Liebowitz MR, Kozak MJ, Davies S, Campeas R, Franklin ME, et al. Randomized, placebocontrolled trial of exposure and ritual prevention, clomipramine, and their combination in the treatment of obsessive-compulsive disorder. American Journal of psychiatry. 2005;162(1):151-61.

14. Shalbafan M, Malekpour F, Tadayon Najafabadi B, Ghamari K, Dastgheib S-A, Mowla A, et al. Fluvoxamine combination therapy with tropisetron for obsessive-compulsive disorder patients: $A$ placebo-controlled, randomized clinical trial. Journal of Psychopharmacology. 2019;33(11):140714.

15. American Psychiatric Association, Koran LM, Hanna GL, Hollander E, Nestadt G, Simpson HB. Practice guideline for the treatment of patients with obsessive-compulsive disorder. 2007.

16. Arabzadeh S, Shahhossenie M, Mesgarpour B, Rezaei F, Shalbafan MR, Ghiasi Z, et al. L-carnosine as an adjuvant to fluvoxamine in treatment of obsessive compulsive disorder: A randomized doubleblind study. Human Psychopharmacology: clinical and experimental. 2017;32(4):e2584.

17. Pigott TA, Seay SM. A review of the efficacy of selective serotonin reuptake inhibitors in obsessivecompulsive disorder. The Journal of clinical psychiatry. 1999;60(2):101-6.

18. Saxena S, Rauch SL. Functional neuroimaging and the neuroanatomy of obsessive-compulsive disorder. Psychiatric Clinics of North America. 2000;23(3):563-86.

19. Suzuki M, Nelson AD, Eickstaedt JB, Wallace K, Wright LS, Svendsen CN. Glutamate enhances proliferation and neurogenesis in human neural progenitor cell cultures derived from the fetal cortex. European Journal of Neuroscience. 2006;24(3):645-53.

20. Karthik S, Sharma LP, Narayanaswamy JC. Investigating the role of glutamate in obsessivecompulsive disorder: Current perspectives. Neuropsychiatric disease and treatment. 2020;16:1003.

21. Hamasaki T, Goto S, Nishikawa S, Ushio Y. Neuronal cell migration for the developmental formation of the mammalian striatum. Brain research reviews. 2003;41(1):1-12.

22. Albelda N, Bar-On N, Joel D. The role of NMDA receptors in the signal attenuation rat model of obsessive-compulsive disorder. Psychopharmacology. 2010;210(1):13-24.

23. Arnold PD, Rosenberg DR, Mundo E, Tharmalingam S, Kennedy JL, Richter MA. Association of a glutamate (NMDA) subunit receptor gene (GRIN2B) with obsessive-compulsive disorder: a preliminary study. Psychopharmacology. 2004;174(4):530-8.

24. Paydary K, Akamaloo A, Ahmadipour A, Pishgar F, Emamzadehfard S, Akhondzadeh S. Nacetylcysteine augmentation therapy for moderate-to-severe obsessive-compulsive disorder: Randomized, double-blind, placebo-controlled trial. Journal of clinical pharmacy and therapeutics. 2016;41(2):214-9. 
25. Zdanys K, Tampi RR. A systematic review of off-label uses of memantine for psychiatric disorders. Progress in Neuro-Psychopharmacology and Biological Psychiatry. 2008;32(6):1362-74.

26. Vlček P, Polák J, Brunovský M, Horáček J. Role of glutamatergic system in obsessive-compulsive disorder with possible therapeutic implications. Pharmacopsychiatry. 2018;51(06):229-42.

27. Pujol J, Soriano-Mas C, Alonso P, Cardoner N, Menchón JM, Deus J, et al. Mapping structural brain alterations in obsessive-compulsive disorder. Archives of general psychiatry. 2004;61(7):720-30.

28. Rauch SL, Wedig MM, Wright Cl, Martis B, McMullin KG, Shin LM, et al. Functional magnetic resonance imaging study of regional brain activation during implicit sequence learning in obsessive-compulsive disorder. Biological psychiatry. 2007;61(3):330-6.

29. Subirà M, Alonso P, Segalàs $C$, Real E, López-Solà C, Pujol J, et al. Brain structural alterations in obsessive-compulsive disorder patients with autogenous and reactive obsessions. PloS one. 2013;8(9):e75273.

30. Sani G, Serra G, Kotzalidis GD, Romano S, Tamorri SM, Manfredi G, et al. The role of memantine in the treatment of psychiatric disorders other than the dementias. CNS drugs. 2012;26(8):663-90.

31. Bakhla AK, Verma V, Soren S, Sarkhel S, Chaudhury S. An open-label trial of memantine in treatmentresistant obsessive-compulsive disorder. Industrial psychiatry journal. 2013;22(2):149.

32. Stewart SE, Jenike EA, Hezel DM, Stack DE, Dodman NH, Shuster L, et al. A single-blinded casecontrol study of memantine in severe obsessive-compulsive disorder. Journal of clinical psychopharmacology. 2010;30(1):34-9.

33. Farnia V, Gharehbaghi H, Alikhani M, Almasi A, Golshani S, Tatari F, et al. Efficacy and tolerability of adjunctive gabapentin and memantine in obsessive compulsive disorder: Double-blind, randomized, placebo-controlled trial. Journal of psychiatric research. 2018 Sep;104:137 - 43. PubMed PMID: 30044966. Epub 2018/07/26. eng.

34. Modarresi A, Sayyah M, Razooghi S, Eslami K, Javadi M, Kouti L. Memantine Augmentation Improves Symptoms in Serotonin Reuptake Inhibitor-Refractory Obsessive-Compulsive Disorder: A Randomized Controlled Trial. Pharmacopsychiatry. 2018 Nov;51(6):263-9. PubMed PMID: 29100251. Epub 2017/11/04. eng.

35. Haghighi M, Jahangard L, Mohammad-Beigi H, Bajoghli $H$, Hafezian $H$, Rahimi A, et al. In a doubleblind, randomized and placebo-controlled trial, adjuvant memantine improved symptoms in inpatients suffering from refractory obsessive-compulsive disorders (OCD). Psychopharmacology (Berl). 2013 Aug;228(4):633 - 40. PubMed PMID: 23525525. Epub 2013/03/26. eng.

36. Yousefzadeh F, Sahebolzamani E, Sadri A, Mortezaei A, Aqamolaei A, Mortazavi SH, et al. 5Hydroxytryptophan as adjuvant therapy in treatment of moderate to severe obsessive-compulsive disorder: a double-blind randomized trial with placebo control. International Clinical Psychopharmacology. 2020;35(5):254-62.

37. Goodman WK, Price LH, Rasmussen SA, Mazure C, Fleischmann RL, Hill CL, et al. The Yale-Brown obsessive compulsive scale: I. Development, use, and reliability. Archives of general psychiatry. 1989;46(11):1006-11. 
38. Berg EA. A simple objective technique for measuring flexibility in thinking. The Journal of general psychology. 1948;39(1):15-22.

39. Heaton RK, Chelune GJ, Talley JL, Kay GG, Curtiss G. Wisconsin Card Sorting Test (WCST): manual: revised and expanded: Psychological Assessment Resources (PAR); 1993.

40. Strauss E, Sherman E, Spreen O. A compendium of neuropsychological tests: New York: Oxford University Press; 2006.

41. Kopp B, Lange F, Steinke A. The reliability of the Wisconsin card sorting test in clinical practice. Assessment. 2021;28(1):248-63.

42. Ghaleiha A, Entezari N, Modabbernia A, Najand B, Askari N, Tabrizi M, et al. Memantine add-on in moderate to severe obsessive-compulsive disorder: randomized double-blind placebo-controlled study. Journal of psychiatric research. 2013 Feb;47(2):175-80. PubMed PMID: 23063327. Epub 2012/10/16. eng.

43. Aboujaoude E, Barry JJ, Gamel N. Memantine Augmentation in Treatment-Resistant ObsessiveCompulsive Disorder: An Open-Label Trial. Journal of Clinical Psychopharmacology. 2009;29(1):515.

44. Kishi T, Matsunaga S, Oya K, Nomura I, Ikuta T, Iwata N. Memantine for Alzheimer's Disease: An Updated Systematic Review and Meta-analysis. Journal of Alzheimer's disease: JAD. 2017;60(2):401-25. PubMed PMID: 28922160. Epub 2017/09/19. eng.

\section{Figures}

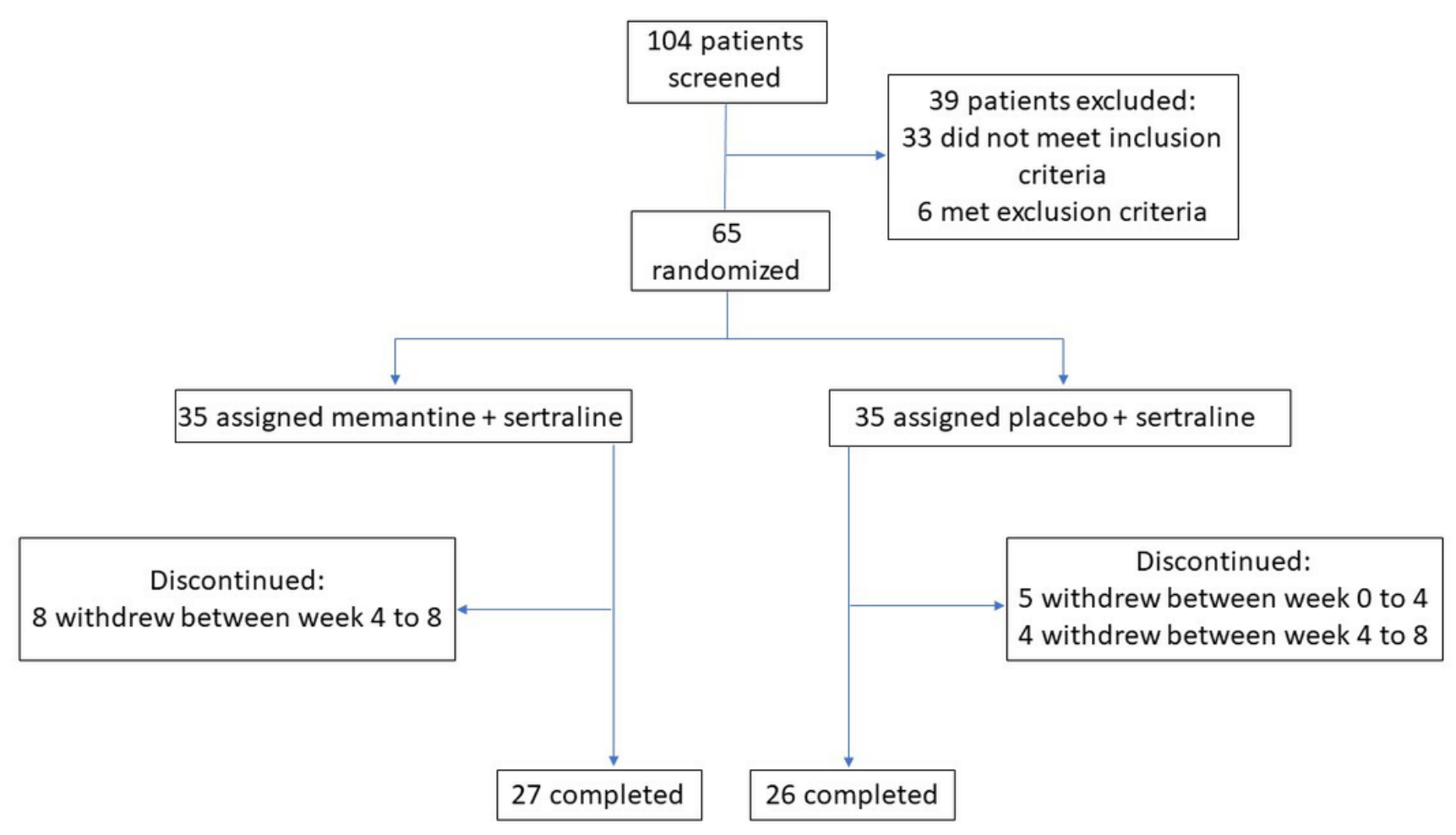


Figure 1

Trial participants' flow-diagram.

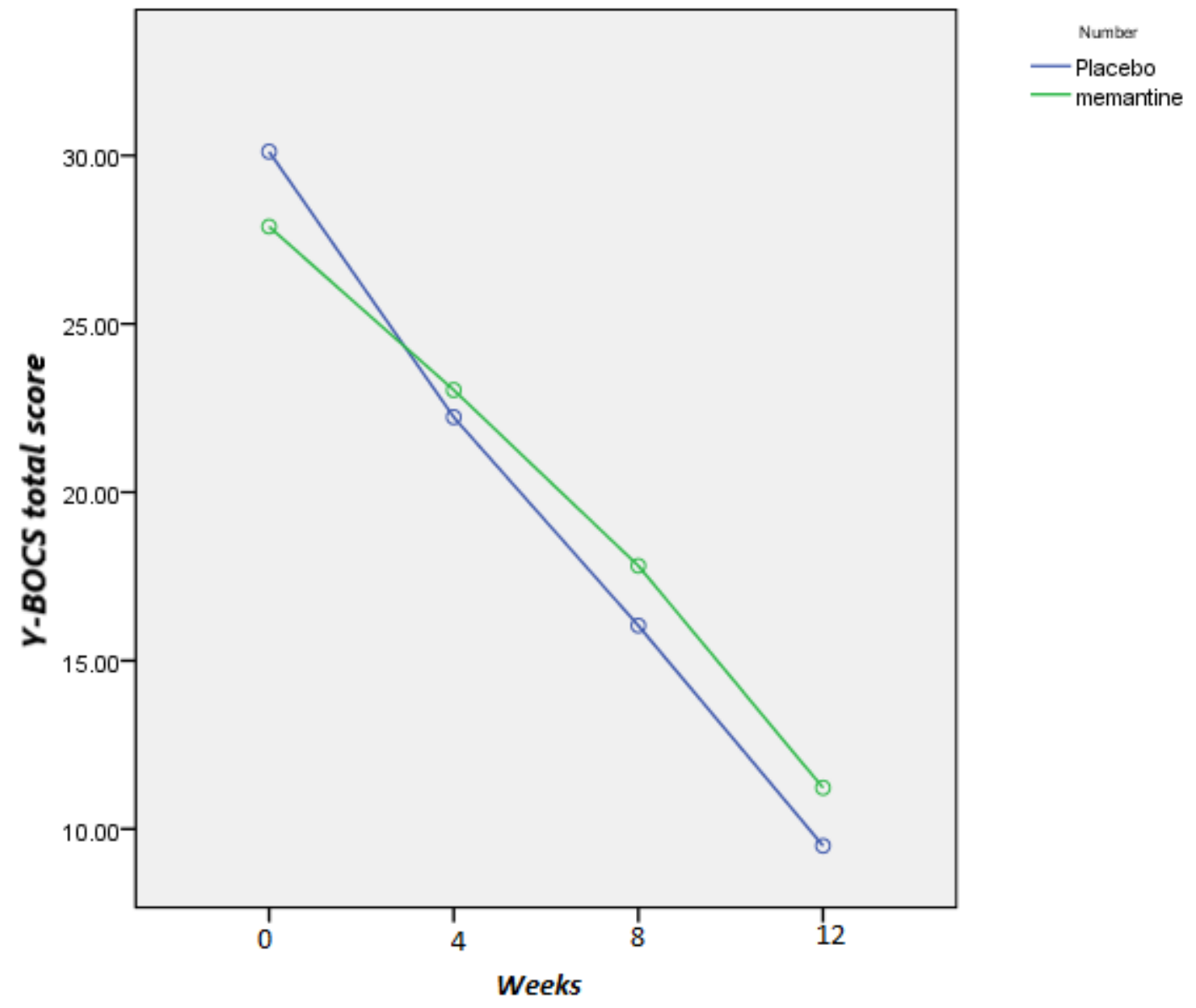

Figure 2

Yale-Brown Obsessive-Compulsive Scale (Y-BOCS) total score trend for each group during the trial course 


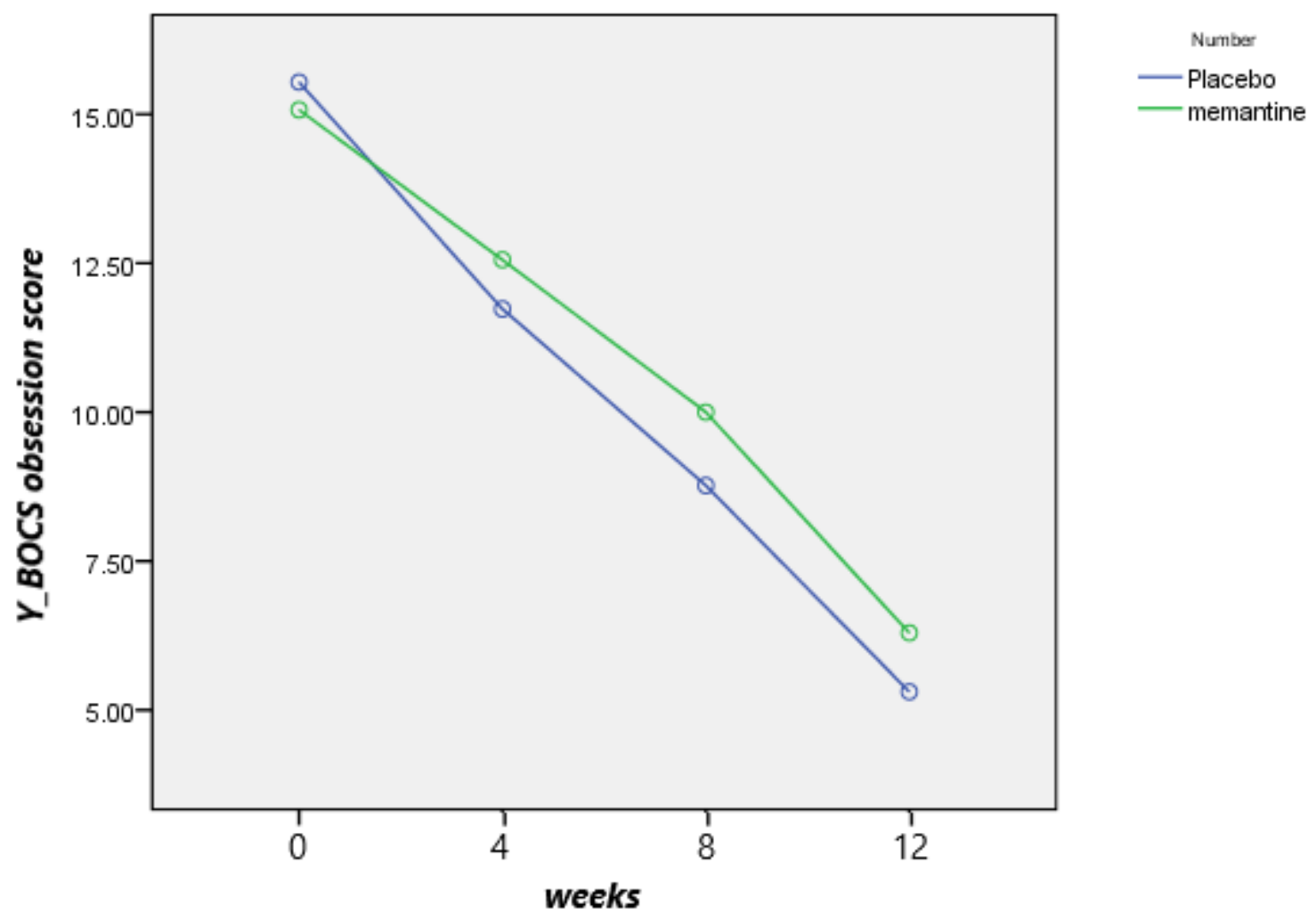

Figure 3

Yale-Brown Obsessive-Compulsive Scale (Y-BOCS) obsession subscale score trend for each group during the trial course 


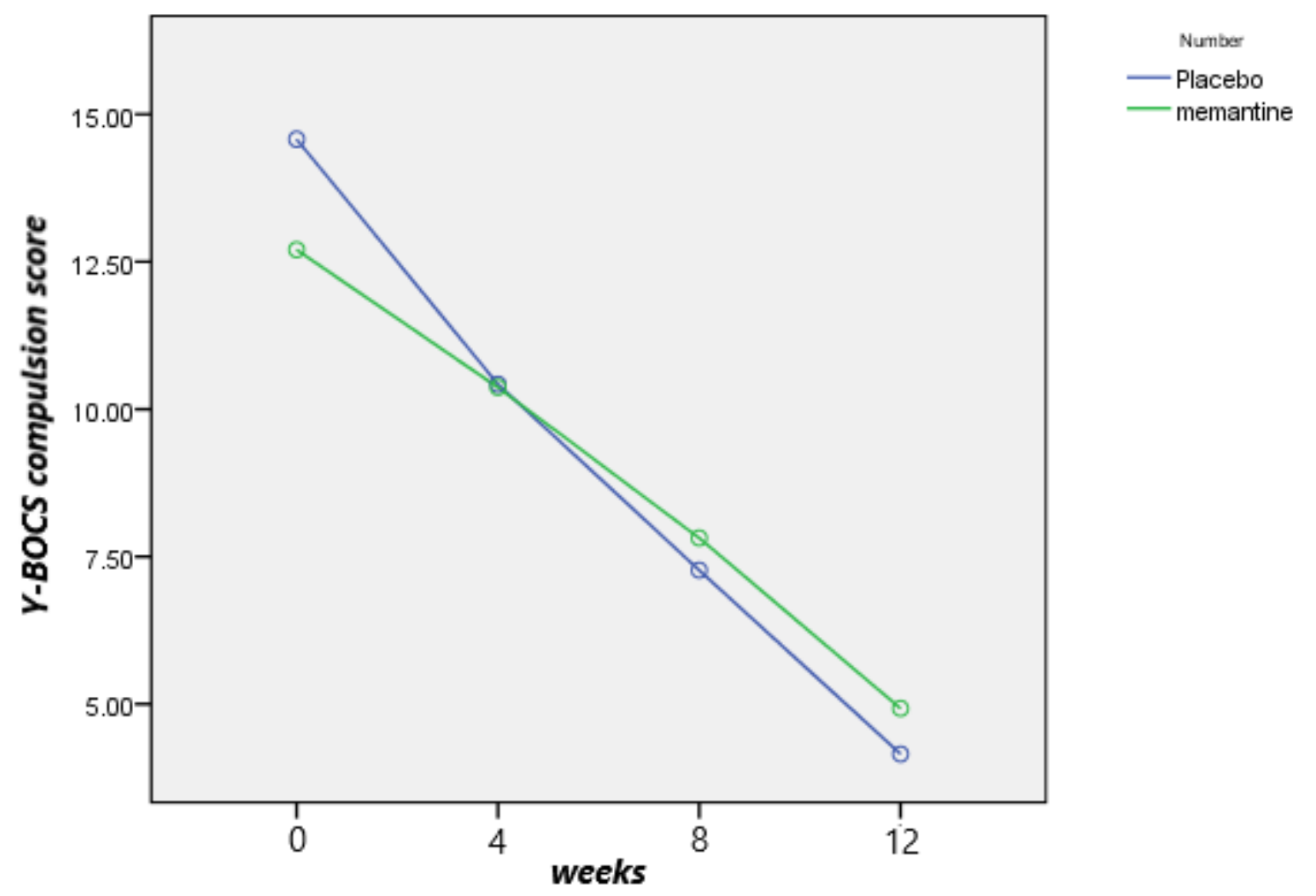

Figure 4

Yale-Brown Obsessive-Compulsive Scale (Y-BOCS) compulsion subscale score trend for each group during the trial course

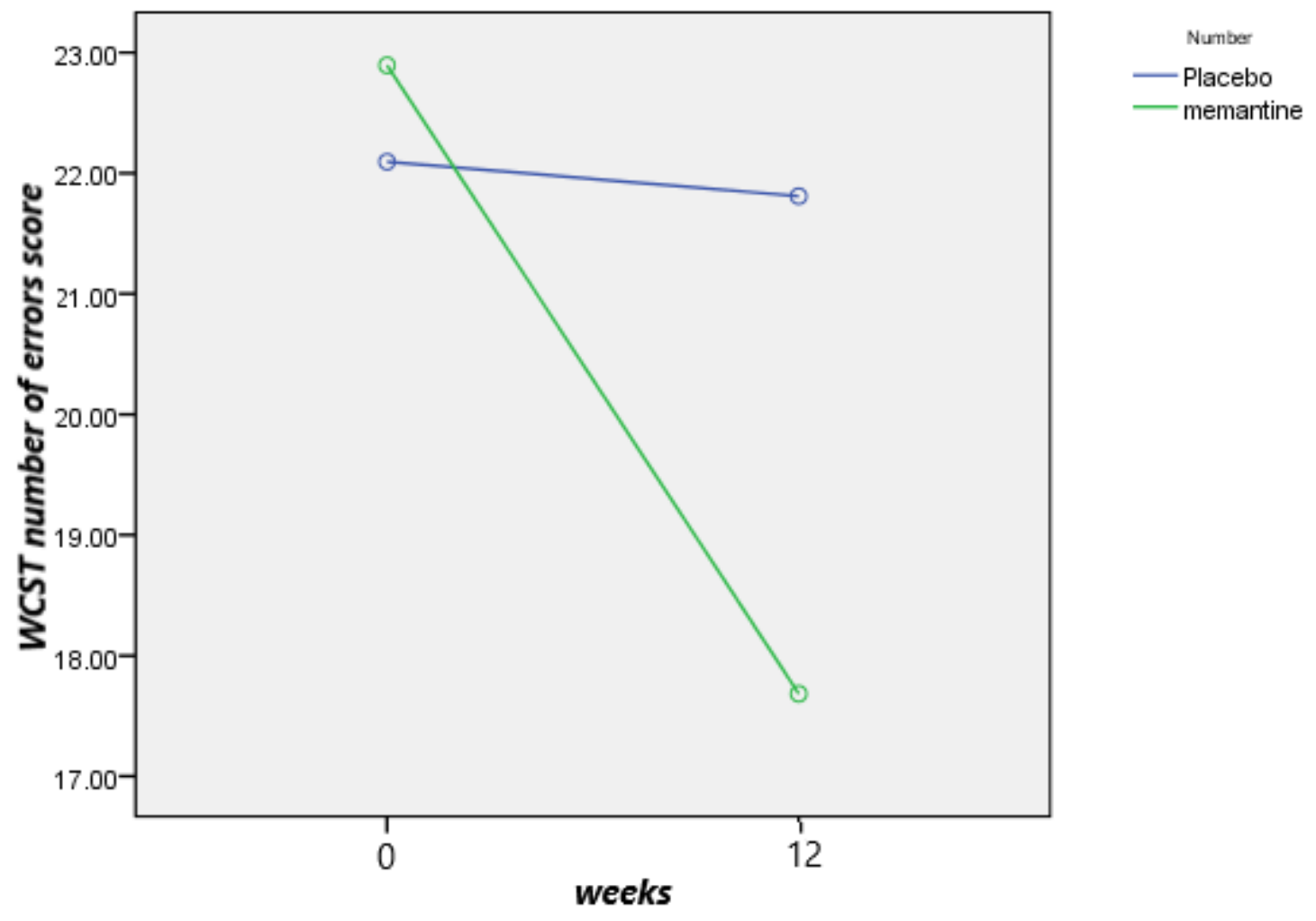

Page 21/23 
Figure 5

WCST number of set-loss errors subscale score trend for each group during the trial course

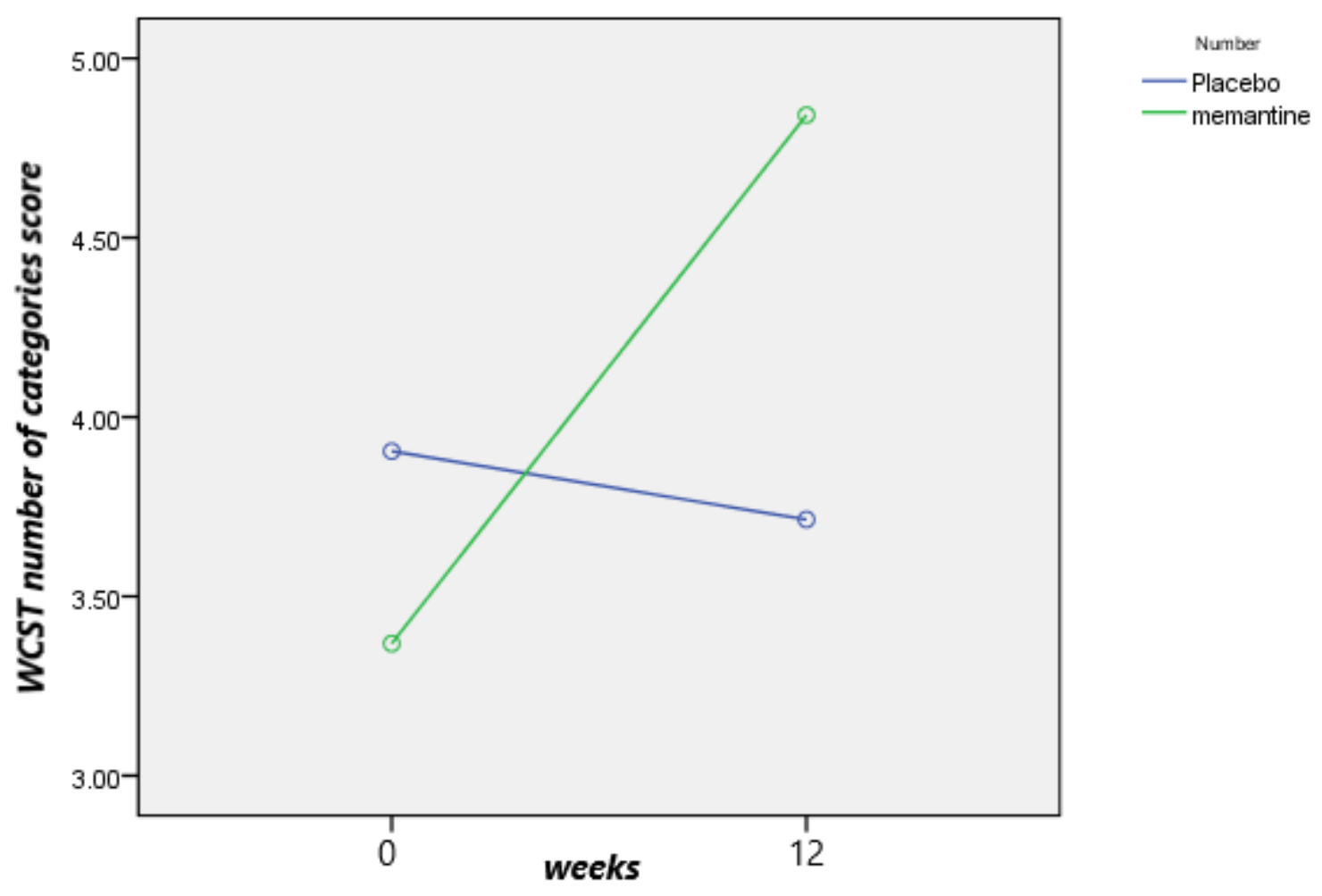

Figure 6

WCST number of categories subscale score trend for each group during the trial course 


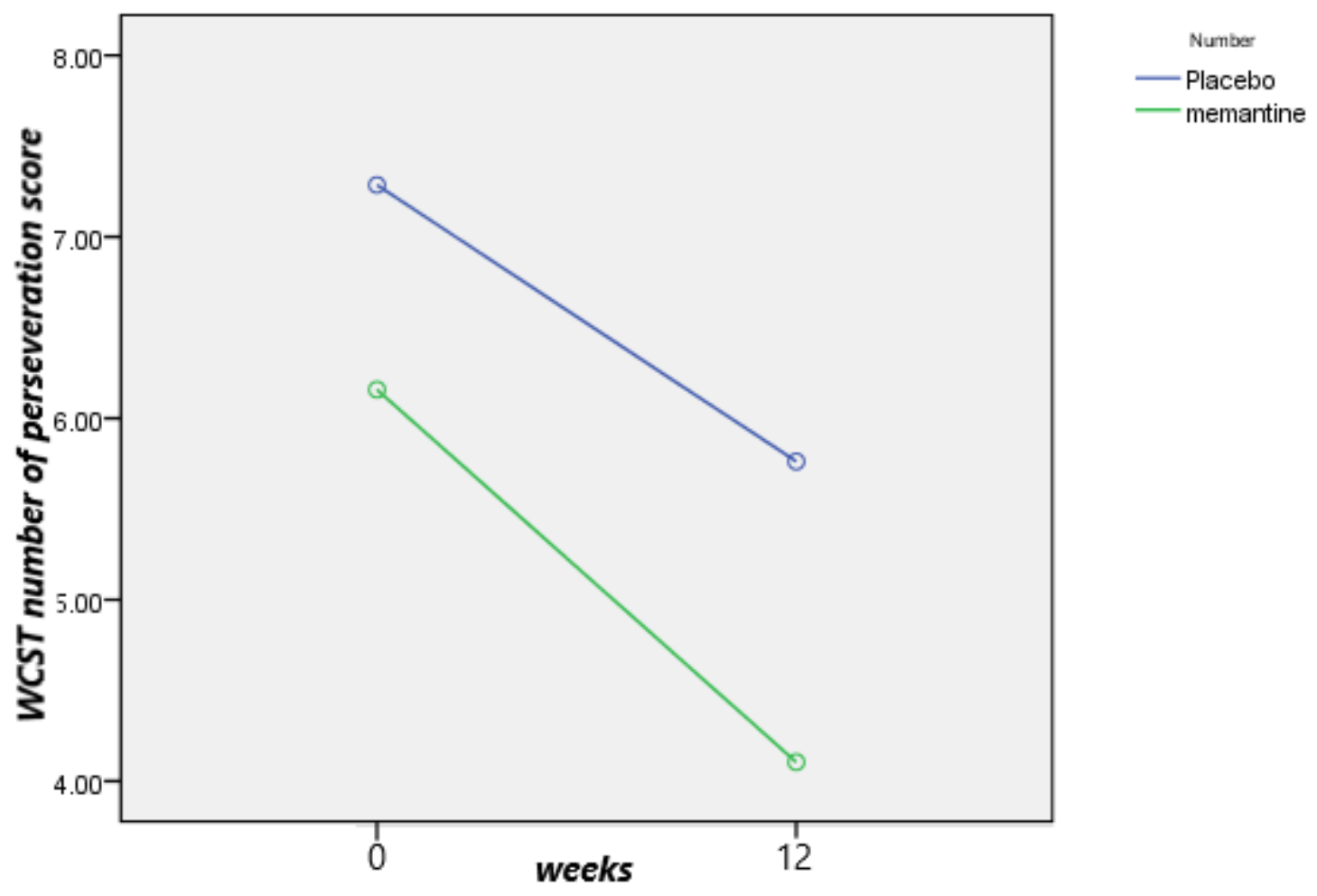

Figure 7

WCST number of perseverative errors subscale score trend for each group during the trial course

\section{Supplementary Files}

This is a list of supplementary files associated with this preprint. Click to download.

- CONSORTChecklist.doc 